\title{
Research on the parameters of producing filamentous textured soybean protein with soybean protein isolated and soybean protein concentrate
}

\author{
Aiping Fei, Xiaoliang Hao, Junyu Jiang, Yong Wang, Yingxue Teng, Yongfei Wang, Yun Gao* \\ University of Science and Technology Liaoning, Anshan China, 114000
}

\begin{abstract}
Textured soybean protein (TSP) is a product made from cooking and extrusion of soybean protein, which has been widely used in food, feed and other industries. This text made soybean protein isolated (SPI) and soybean protein concentrate (SPC) as the raw materials to produce filamentous protein production. By experiment, the influence of puffing temperature, screw speed and feed rate on the quality of the protein products was studied. Finally it was concluded that when the temperature of the barrel was $152{ }^{\circ} \mathrm{C}$, the screw rotation speed was $119 \mathrm{rpm}$, the feed rate was $0.426 \mathrm{~kg} / \mathrm{min}$, the TSP product had the biggest expansion degree.
\end{abstract}

\section{INTRODUCTION}

Protein is one of the important nutrients in food and plays an important role in improving human immunity. Soybean is rich in soybean protein, and more efficient proteins are developed from soybean, which is beneficial to the improvement of human life quality.

Soybean is rich in protein, and has been an important cash crop which has been widely cultivated all around the world. As the raw material for soybean oil, soy-based products, such as soymilk and tofu, soybean is widely consumed in China ${ }^{[1]}$. At present, the processing degree of soybean is low, which is based on primary processing. How to further process the soybean and improve the added value of soybean products is one of the key problems to be solved in soybean production.

As a high-grade product, textured soybean protein (TSP) is more and more popular in the market because of its high protein content, low cost, simple production process and tastes like meat. At present, TSP products in the market have the bean smell and the structure are in a bad state. One main reason is partly because the raw materials are improperly selected, and the other reason is that the processing technology is improperly selected ${ }^{[2-4]}$.

So far, there have been few studies on textured soybean protein production. In fact, many parameters such as the temperature, feed rate, screw rotation speed would affect the quality of TSP products ${ }^{[5-7]}$.

In this study, soybean protein isolated (SPI) and soybean protein concentrate (SPC) were used as raw materials, flour and corn flour were used as auxiliary materials to produce TSP by improving processing technology and controlling processing parameters. The protein content of the product was high, the expansion degree was good, and the taste of the product was better.
We hope our research might provide more reference for actual production.

\section{MATERIALS AND METHODS}

\subsection{Materials}

Soybean protein isolated powder (Harbin Gongda Protein Factory), soybean protein concentrate powder (Qinhuangdao Jinhai Cereals and Oils Co., Ltd.), other raw materials are commercially available.

\subsection{Instruments}

Soxhlet extractor (Tianjin Tianke Glass Instrument Manufacturing Co., Ltd.), micro-Kjeldahl nitrogen plant (Tianjin Tianke Glass Instrument Manufacturing Co., Ltd.), DS56-III twin-screw extruder (Ji Nan Saixin Extrusion Machinery Co., Ltd. the company).

\subsection{Experimental}

\subsubsection{Determination of main raw material composition}

The raw material included SPI, SPC, flour, corn flour. Because the usage amount of flour and corn flour was very few, their nutrients were refer to market averages. The test items included protein, fat, water, ash and nitrogen solubility index.

\subsubsection{The production process}

\footnotetext{
a Corresponding author: Yuner9111@163.com
} 
The raw and auxiliary materials were weighed in a certain proportion, and mixed well. The twin-screw extruder needed to warm up half an hour in advance. After the machine parameters were set, the feed production test was carried out. Pay attention to the changes of materials and processing parameters in the production process at any time, and turned off the machine switch after the experiment. The expansion degree of the product was tested to analyze the quality difference of the product under different experimental conditions.

\section{RESULTS AND DISSCUSSION}

\subsection{Raw material composition determination results}

Table 1. Results of determination of main raw material components in extrusion test.

\begin{tabular}{cccccc}
\hline Raw & Protein/ & Fat/\% & Water/ & Ash/\% & $\begin{array}{c}\text { Nitrogen } \\
\text { solubility } \\
\text { material }\end{array}$ \\
$\begin{array}{ccccc}\% \\
\text { SPC }\end{array}$ & 71.3 & 0.85 & 5.3 & 5.5 & 71.6 \\
SPI & 91.5 & 0.65 & 3.4 & 3.7 & 89.7 \\
\hline
\end{tabular}

It could be seen from Table 1 that the protein contents of both main raw materials were greater than $50 \%$, and the nitrogen solubility index was greater than $70 \%$, which was consistent with the requirements of the production of tissue proteins for the raw materials used. In this research, the ratio of raw materials was: SPC $(40 \%)$, SPI $(40 \%)$, flour $(10 \%)$, and corn flour $(10 \%)$. Such ratio not only ensured normal production, but also met the requirements of high protein and low $\operatorname{cost}^{[8]}$.

\subsection{Effect of single factor effect on the expansion degree $(Y)$}

In order to better study the effect of production conditions on TSP, the mathematical model was used to optimize the condition. Three main factors, such as the temperature, screw speed, and feed rate were chosen (Table 2).

Table 2. Experimental factors and their range of variation.

\begin{tabular}{ccc}
\hline No & Factors & Range of variation \\
\hline $\mathrm{Z} 1$ & Temperature $\left({ }^{\circ} \mathrm{C}\right)$ & $130 \sim 160$ \\
$\mathrm{Z} 2$ & Screw speed $(\mathrm{rpm})$ & $60 \sim 120$ \\
$\mathrm{Z} 3$ & Feed rate $(\mathrm{kg} / \mathrm{min})$ & $0.2 \sim 0.6$ \\
\hline
\end{tabular}

\subsubsection{Effect of temperature $\left(X_{1}\right)$ on the expansion degree $(Y)$}

In order to intuitively find out the influence of the barrel temperature $\left(X_{1}\right)$ on the index, set $X_{2}=X_{3}=-1$;
$\mathrm{X}_{2}=\mathrm{X}_{3}=0 ; \mathrm{X}_{2}=\mathrm{X}_{3}=1$, and the following three equations could be obtained:

$$
\begin{aligned}
\mathrm{Y}_{1}=3.20+0.39 \mathrm{X}_{1}-0.23 \mathrm{X}_{1}^{2} \\
\mathrm{Y}_{2}=3.58+0.39 \mathrm{X}_{1}-0.23 \mathrm{X}_{1}^{2} \\
\mathrm{Y}_{3}=3.36+0.39 \mathrm{X}_{1}-0.23 \mathrm{X}_{1}^{2}
\end{aligned}
$$

The curves of the equations were shown in Figure 1:

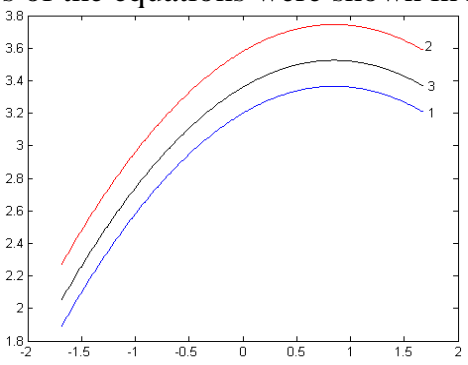

Figure 1. Effect of temperature on the expansion degree

As shown in Figure 1, the curve of the processing temperature on the expansion degree was parabolic. When the processing temperature was increased, the expansion degree of the product increased, but under a certain extent, the expansion degree decreased. The reasion was that within a certain temperature range, increasing the temperature made the material more favorable for gelatinization and increased the expansion degree of the product.

\subsubsection{Effect of screw speed $\left(X_{2}\right)$ on the expansion degree $(Y)$}

$X_{1}$ and $X_{3}$ were fixed and the following equation could be obtained:

$$
\begin{aligned}
& Y_{1}=2.56-0.02 X_{2}{ }^{2} \\
& Y_{2}=3.58+0.27 \mathrm{X}_{2}^{2} \\
& Y_{3}=2.96+0.56 X_{2}^{2}
\end{aligned}
$$

The curves of the equations were shown in Figure 2:

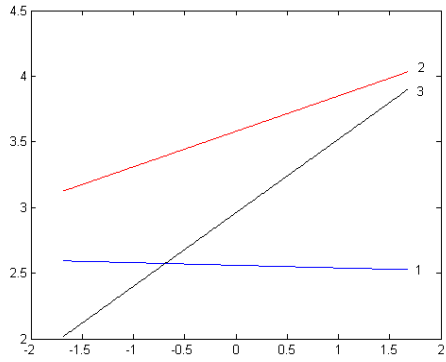

Figure 2. Effect of screw speed on the expansion degree.

As shown in Figure 2, curve 1 was relatively flat, indicating that when the barrel temperature and the feed rate were very slow, it was difficult to expand the material, and the material had to be expanded to have a certain temperature to change the internal structure. For curve 2 and curve 3 , it could be seen that at a certain temperature and feed rate, as the screw speed increased, the internal action of the material increased, and the expansion degree increased. For the actual production, the screw speed could be increased within a certain range to increase the product expansion degree and output, but the screw speed could not be too fast, otherwise it was easy to block the material and the product was not expanded ${ }^{[8-13]}$. 


\subsubsection{Effect of feed rate $\left(X_{3}\right)$ on the expansion degree $(Y)$}

Fixing $X_{1}$ and $X_{2}$, the following equations could be obtained:

$$
\begin{aligned}
Y_{1} & =2.69-0.48 X_{3}-0.59 X_{3}{ }^{2} \\
Y_{2} & =3.58-0.19 X_{3}-0.59 X_{3}^{2} \\
Y_{3} & =4.01+0.10 X_{3}-0.59 X_{3}{ }^{2}
\end{aligned}
$$

The curves they presented were shown in Figure 3.

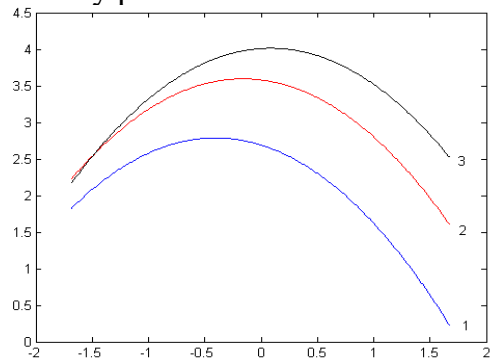

Figure 3. Effect of feed rate on the expansion degree.

As shown in Figure 3, within a certain range, as the temperature of the barrel rised, the internal gelatinization of the product was enhanced, and the expansion degree of the product was increased, but when the temperature exceeded a certain temperature, the product would be burnt, the structure became hard, the surface was browned, and the expansion degree was lower. For actual production, the product could be expanded within a certain temperature range, and the temperature was slightly higher, which was more conducive to product expansion.

\subsection{Two-factor effect analysis}

\subsubsection{Effect of screw speed $\left(X_{2}\right)$ and feed rate $\left(X_{3}\right)$ on the expansion degree}

By fixing the barrel temperature $\left(\mathrm{X}_{1}\right)$ at the 0 level, a model of the screw speed $\left(\mathrm{X}_{2}\right)$ and the feed rate $\left(\mathrm{X}_{3}\right)$ versus the expansion degree could be obtained: $\mathrm{Y}=3.58+0.27 \mathrm{X}_{2}-0.19 \mathrm{X}_{3}+0.29 \mathrm{X}_{2} \mathrm{X}_{3}-0.59 \mathrm{X}_{3}^{2}$
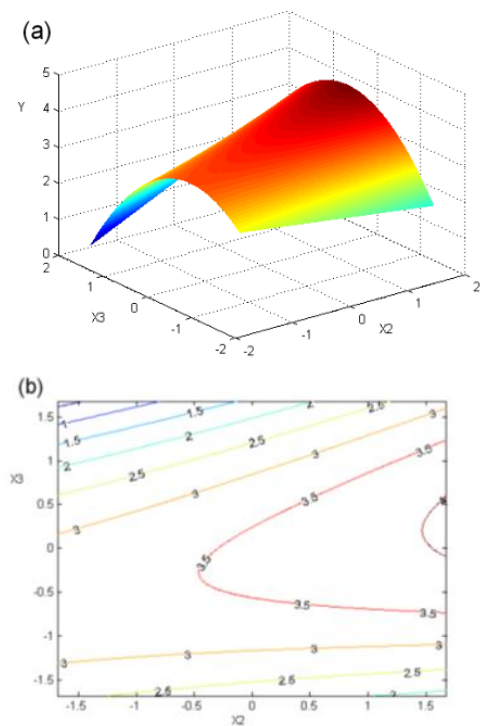

Figure 4. Effect of screw speed and feed rate on the expansion degree.
It could be seen from the Figure 4 that the screw speed $\mathrm{X}_{2}=1.48 \sim 1.68$, and the feed rate $\mathrm{X}_{3}=-0.2 \sim 0.45 \mathrm{had}$ the largest expansion degree. This range could be used as the scope of the subsequent verification experiment. The mechanism was that when the screw speed and feed rate were larger, the processing ability began to be stronger. The extreme points were selected as: $\mathrm{X}_{1}=0, \mathrm{X}_{2}=1.68$, $\mathrm{X}_{3}=0.45$, and the subsequent experiments were verified.

\subsubsection{Effect of barrel temperature $\left(X_{1}\right)$ and feed rate $\left(X_{3}\right)$ on the expansion degree}

By fixing the screw speed $\left(\mathrm{X}_{2}\right)$ at the 0 level, a model of the barrel temperature $\left(\mathrm{X}_{1}\right)$ and the feed rate $\left(\mathrm{X}_{3}\right)$ versus the expansion degree could be obtained:

$$
\mathrm{Y}=3.58+0.39 \mathrm{X}_{1}-0.19 \mathrm{X}_{3}-0.23 \mathrm{X}_{1}^{2}-0.59 \mathrm{X}_{3}^{2}
$$
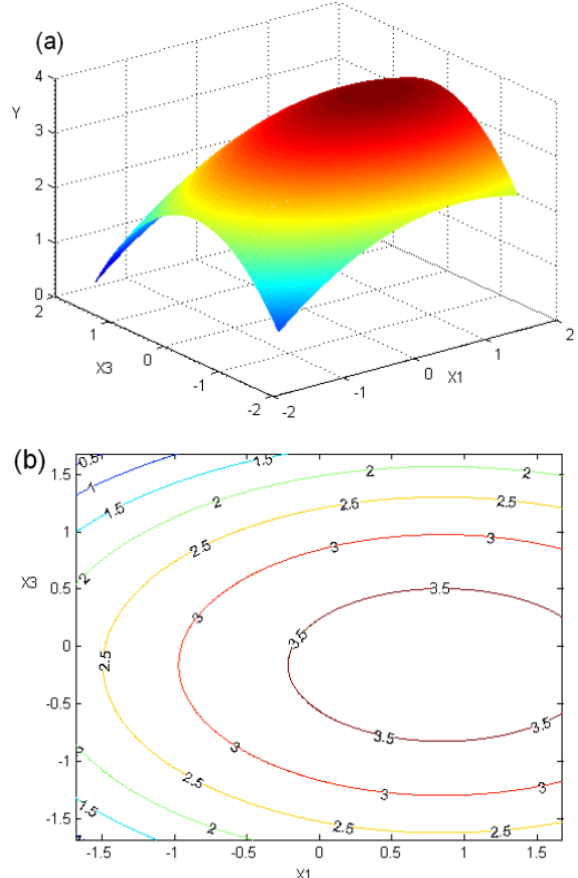

Figure 5. Effect of barrel temperature and feed rate on the expansion degree.

When the barrel temperature $\mathrm{X}_{1}=-0.3 \sim 1.68$, the product had the highest expansion degree; when the feed rate $\mathrm{X}_{3}=-0.75 \sim 0.45$, the product had the highest expansion degree, which could be used as the scope of subsequent verification experiments. The mechanism was that when the temperature of the barrel was higher, the interaction among the raw materials was enhanced, the product was more conducive to puffing. The extreme point was selected as: $X_{1}=1.68, X_{2}=0, X_{3}=0.45$.

\subsubsection{Influence of barrel temperature $\left(X_{1}\right)$ and screw speed $\left(X_{2}\right)$ on the expansion degree}

$$
\mathrm{Y}=3.58+0.39 \mathrm{X}_{1}+0.27 \mathrm{X}_{2}-0.23 \mathrm{X}_{1}^{2}
$$



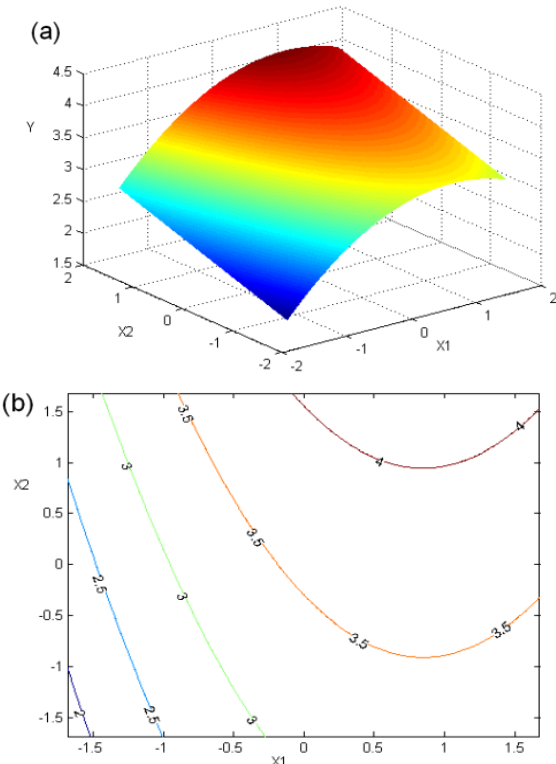

Figure 6. Effect of temperature and screw speed on the expansion degree.

When the barrel temperature $X_{1}=-0.1 \sim 1.68$, the product had the highest expansion degree; when the screw speed $\mathrm{X}_{2}=0.95 \sim 1.68$, the product had the highest expansion degree, which could be used as the scope of subsequent verification experiments. The mechanism was that when the temperature of the barrel was higher, the interaction among the raw materials was enhanced, which was more conducive to puffing; when the screw was higher, the product feed began to be smoother. The extreme point was selected as: $\mathrm{X}_{1}=1.68, \mathrm{X}_{2}=1.68, \mathrm{X}_{3}=$ 0 .

\subsection{Optimization of process parameters}

Regression equation for the expansion degree: $\mathrm{Y}=3.58+0.39 \mathrm{X}_{1}+0.27 \mathrm{X}_{2}-0.19 \mathrm{X}_{3}+0.29 \mathrm{X}_{2} \mathrm{X}_{3}-0.23 \mathrm{X}_{1}{ }^{2}$ $0.59 \mathrm{X}_{3}^{2}$

The optimized condition was that: when $\mathrm{X}_{1}=0.85$, $\mathrm{X}_{2}=-3.13, \mathrm{X}_{3}=-0.93$, the $\mathrm{Y}$ value was equal to 2.57 . Because the range of $X$ was between -1.682 and 1.682, $X$ was out of range, therefore, it had no meaning for this equation and should be discarded.

The three extreme points were obtained by the two factors and the extreme points were obtained by the optimization program. Some random datas were also selected as the experimental parameters, The extrusion experiment optimized parameters were shown in Table 3.

Table 3. Extrusion experiment optimized parameters.

\begin{tabular}{cccccccc} 
No & $\mathrm{X}_{1}$ & $\mathrm{X}_{2}$ & $\mathrm{X}_{3}$ & $\begin{array}{c}\mathrm{Y}(\mathrm{By} \\
\text { equation })\end{array}$ & $\begin{array}{c}\mathrm{Y}(\mathrm{By} \\
\text { experiment })\end{array}$ & Error & $\begin{array}{c}\text { Fractional } \\
\text { error(\%) }\end{array}$ \\
\hline 1 & 0 & 1.68 & 0.45 & 4.04 & 3.85 & -0.19 & 4.70 \\
2 & 1.68 & 0 & 0.45 & 3.70 & 3.92 & 0.20 & 5.41 \\
3 & 1.68 & 1.68 & 0 & 4.04 & 4.19 & 0.15 & 3.71 \\
4 & 0.82 & 1.62 & 0.22 & 4.15 & 4.29 & 0.14 & 3.37 \\
5 & 0 & 0 & 0 & 3.58 & 3.73 & 0.15 & 4.19 \\
6 & -0.5 & 0 & 0.5 & 2.94 & 3.21 & 0.27 & 9.18 \\
\hline
\end{tabular}

As shown in Table 3, No 4 had the highest $\mathrm{Y}$ value, no matter by equation and by experiment. The $\mathrm{X}_{1}, \mathrm{X}_{2}, \mathrm{X}_{3}$ were all in the range of -1.68 and 1.68 , it was seen that the values obtained were shown to be valid. The error and fractional error were relatively low, indicating a good reproducibility of the experiment, we could use equations to simulate actual production. Changed the code of the equation into the actual operating parameters, and we got the optimal condition was that: when the temperature of the main barrel was $152^{\circ} \mathrm{C}$; the screw speed was $119 \mathrm{rpm}$; the feed rate was $0.426 \mathrm{~kg} / \mathrm{min}$, the expansion degree was highest.

\section{Conclusions}

In our experiment, the optimal condition for the production of filamentous TSP was obtained by equation modeling and experimental operation. It was proved that the equation modeling was a better method to optimize the optimal condition. The error between the equation modeling and experimental operation was lower $(<10 \%)$, it illustrated the feasibility of the method. We hope our research might provide more reference for actual production.

\section{Acknowledge}

This work was financially supported by Liaoning Natural Science Foundation Project (project number: 20170520093, 20170540466), Liaoning Provincial Education Office Service Local Project (project number: 2017FWDF05).

\section{References}

1. Li, Y.H., Guan, R.X., Liu, Z.X., Ma, Y.S., Wang, L.X., Li, L.H., et al., Genetic structure and diversity of cultivated soybean (Glycine max (L.) Merr.) landraces in China. Theor. Appl. Genet, 117, 857871(2008)

2. de Kruif, C.G., Weinbreck, F., de Vries, R., Complex coacervation of proteins and anionic polysaccharides. Curr. Opin. Colloid Interface Sci, 9 (5), 340-349 (2004)

3. Lemetter, C.Y.G., Meeuse, F.M., Zuidam, N.J., Control of the morphology and the size of complex coacervate microcapsules during scale-up. AIChE, 55 (6), 1487-1496 (2009)

4. Yan Li Du, Guo Qing Huang, Hai Ou Wang, Jun Xia Xiao. Effect of high coacervation temperature on the physicochemical properties of resultant microcapsules through induction of Maillard reaction between soybean protein isolate and chitosan. Journal of Food Engineering, 234, 9197(2018)

5. K.E. Preecea, N. Hooshyarb, N.J. Zuidam. Whole soybean protein extraction processes: A review. Innovative Food Science and Emerging Technologies, 43, 163-172(2017) 
6. Zhang Qiuhui, Yue Xiqing, Li Miaoyun, et al. Application of Soybean tissue protein in Recombinant Meat products. Food and fermentation Industry, (1), 101-105(2015)

7. Liu Fusheng. Study on the production of tissue protein by medium-sized twin-screw extruder. The Master thesis of Northeast Agricultural University of China, 11-10, 35-39(2006)

8. Yang Qingyu. High moisture cooking extruded noodle food and its application in spicy food. The Master thesis of Northeast Agricultural University, 10-20(2008)

9. Zhu Feng, Zhu Yinyue, Li Tianjiao, et al. Study on the production of instant sausages with soybean meal systematized products. Food and feed industry, (10), 20-25(2016)

10. Hao Xiaoliang, Liu Yi. Comparison of fibrous Soybean tissue protein with General tissue protein. Food Industry Technology, (9), 113-114(2007)

11. Hao Xiaoliang, Sun Yuemei, Jiang Lianzhou, et al. Preparation of Soybean tissue protein Ham sausage. Soybean Bulletin, (3), 23-25(2007)

12. Badrie N, Mellowes W A. Effect of extrusion variables on cassar extrudate. Food Science, 56(5), 1443(1991)

13. Camire M L. Protein functionality modification by extrusion cooking. JAOCS, 68(3), 200-204(1991) 